\title{
Electrical Conduction Mechanism in Solid Polymer Electrolytes: New Concepts to Arrhenius Equation
}

\author{
Shujahadeen B. Aziz ${ }^{1}$ and Zul Hazrin Z. Abidin² \\ ${ }^{1}$ Department of Physics, Faculty of Science and Science Education, University of Sulaimani, \\ Kurdistan Regional Government, Sulaimani, Iraq \\ ${ }^{2}$ Centre for Ionics University of Malaya (CIUM), Department of Physics, Faculty of Science, University of Malaya, \\ 50603 Kuala Lumpur, Malaysia \\ Correspondence should be addressed to Shujahadeen B. Aziz; shujaadeen78@yahoo.com
}

Received 18 April 2013; Revised 4 July 2013; Accepted 5 July 2013

Academic Editor: Luisa Torsi

Copyright (C) 2013 S. B. Aziz and Z. H. Z. Abidin. This is an open access article distributed under the Creative Commons Attribution License, which permits unrestricted use, distribution, and reproduction in any medium, provided the original work is properly cited.

Solid polymer electrolytes based on chitosan $\mathrm{NaCF}_{3} \mathrm{SO}_{3}$ have been prepared by the solution cast technique. X-ray diffraction shows that the crystalline phase of the pure chitosan membrane has been partially disrupted. The fourier transform infrared (FTIR) results reveal the complexation between the chitosan polymer and the sodium triflate (NaTf) salt. The dielectric constant and DC conductivity follow the same trend with NaTf salt concentration. The increase in dielectric constant at different temperatures indicates an increase in DC conductivity. The ion conduction mechanism follows the Arrhenius behavior. The dependence of DC conductivity on both temperature and dielectric constant $\left(\sigma_{\mathrm{dc}}\left(T, \varepsilon^{\prime}\right)=\sigma_{0} e^{-E_{a} / K_{B} T}\right)$ is also demonstrated.

\section{Introduction}

Ion conducting polymers are an active area of study in materials research. They are prepared by complexing polymers containing polar groups with alkali metal salts [1]. Being light weight and flexible $[2,3]$, attempts have been made to use solid polymer electrolytes in solid-state electrochemical devices such as batteries, fuel cells, electrochromic displays, and smart windows [4]. Polymer electrolytes usually contain both crystalline and amorphous phases. It has been reported that the ion conduction takes place primarily in the amorphous phase [5].

Chitosan is a derivative of chitin which can be obtained from crab and shrimp shells. Chitosan is produced from deacetylation of chitin to overcome the solubility limitation of chitin in common solvents [6]. Due to the $\mathrm{NH}_{2}$ and $\mathrm{OH}$ functional groups that can serve as conjunction sites, chitosan is a good sorbent with high affinity for transition metal ions [7]. Chitosan has good film forming ability, porous scaffolds, and hydrogels [8]. Ion-conducting polymer electrolytes based on chitosan have also been reported [9-16]. From the fundamental point of view, ionic conduction in polymer electrolytes is still poorly understood. Ion transport is complex and depends on factors such as salt concentration, dielectric constant of host polymer, degree of salt dissociation and ion aggregation, and mobility of polymer chains [17]. Dielectric analysis of ion conducting polymer electrolytes can provide information on ion transport behavior and ionic/molecular interaction in solid polymer electrolytes [18]. This is due to the fact that dielectric constant is both frequency and temperature dependent [19]. Recently Petrowsky and Frech $[20,21]$ hypothesized that the DC conductivity is not only a function of temperature, but also is dependent on the dielectric constant in organic liquid electrolytes. They have also interpreted the non-Arrhenian behavior of DC conductivity as a result of dependence of pre-exponential factor, $\sigma_{o}$, on the dielectric constant, $\sigma_{\mathrm{dc}}\left(T, \varepsilon^{\prime}\right)=\sigma_{o}\left(\varepsilon^{\prime}(T)\right) e^{-E_{a} / K_{B} T}$.

In view of the previously mentioned, the main objective of the present work is to investigate the Petrowsky and Frech postulate for solid polymer electrolyte based on chitosan: $\mathrm{NaCF}_{3} \mathrm{SO}_{3}$, as well as to investigate the physics behind the relationship between DC conductivity and dielectric constant. The X-ray diffraction (XRD), fourier transform infrared (FTIR), and electrical impedance spectroscopy (EIS) have been used to characterize the chitosan-based solid electrolytes prepared in this study. 


\section{Experimental Details}

2.1. Materials and Sample Preparation. The polymer electrolytes were prepared by the solution cast technique. NaTf and chitosan (from crab shells; $\geq 75 \%$ deacetylated, Sigma) have been used as the raw materials in this study. One gram of chitosan (CS) was dissolved in $100 \mathrm{~mL}$ of $1 \%$ acetic acid solution. The mixture was stirred continuously with a magnetic stirrer for several hours at room temperature until the chitosan powder has completely dissolved. To these sets of solution 2 to $10 \mathrm{wt} \%$ of NaTf was added separately and the mixtures were stirred continuously until homogeneous solutions were obtained. The samples were coded as CS0 (pure chitosan acetate), CS2, CS4, CS6, CS8, and CS10 for CS with 2 wt $\%$, CS with 4 wt $\%$, CS with 6 wt $\%$, CS with 8 wt $\%$, and CS with $10 \mathrm{wt} \%$ NaTf. The solutions were then cast into different plastic petri dish and left to dry at room temperature in order to allow complete evaporation of solvent. The films were kept in desiccators with silica gel desiccant for further drying process.

2.2. X-Ray Diffraction. In this paper, XRD was performed to study the nature of complexation between $\mathrm{NaCF}_{3} \mathrm{SO}_{3}$ and chitosan. The XRD was recorded at room temperature using $\mathrm{X}$-ray diffractometer (Bruker AXS) with operating voltage and current of $40 \mathrm{kV}$ and $40 \mathrm{~mA}$, respectively. The samples were scanned with a beam of monochromatic, X-radiation of wavelength $\lambda=1.5406 \AA$, and the glancing angles were in the range of $5^{\circ} \leq 2 \theta \leq 80^{\circ}$ with a step size of $0.1^{\circ}$. To study the amorphousness of the samples the coherent length was calculated using the following relation:

$$
L=\frac{0.9 \lambda}{\Delta 2 \theta_{b} \cos \theta_{b}},
$$

where $\lambda$ is $\mathrm{X}$-ray wavelength, $\Delta 2 \theta_{b}$ is full width at half maximum, and $\theta_{b}$ is the angle of the peak.

2.3. Fourier Transform Infrared (FTIR) Spectroscopy. Pure chitosan and chitosan-salt complexes were analyzed with FTIR spectrophotometer (Thermo Scientific/Nicolet iS10) in the wave number region between 4000 and $400 \mathrm{~cm}^{-1}$. The resolution for each spectrum was $2 \mathrm{~cm}^{-1}$.

2.4. Electrical Impedance Spectroscopy (EIS). Complex impedance spectroscopy gives information on electrical properties of materials and their interface with electronically conducting electrodes. The solid polymer electrolyte (SPE) films were cut into small discs ( $2 \mathrm{~cm}$ diameter) and sandwiched between two stainless steel electrodes under spring pressure. The impedance of the films was measured in the frequency range from $50 \mathrm{~Hz}$ to $1000 \mathrm{kHz}$ using the HIOKI $3531 \mathrm{Z} \mathrm{Hi-tester}$ which was interfaced to a computer. Measurements were also made at temperatures ranging between $303 \mathrm{~K}$ and $363 \mathrm{~K}$. The software controls the measurements and calculates the real $\left(Z^{\prime}\right)$ and imaginary $\left(Z^{\prime \prime}\right)$ parts of impedance. $Z^{\prime}$ and $Z^{\prime \prime}$ data were presented as a Nyquist plot, and the bulk resistance was obtained from the intercept of the plot with the real impedance axis. The conductivity then can be calculated from the following equation:

$$
\sigma_{\mathrm{dc}}=\left(\frac{1}{R_{b}}\right) \times\left(\frac{t}{A}\right) .
$$

In (2), $t$ is the thickness and $A$ is the area of the film.

The real $\left(Z^{\prime}\right)$ and imaginary $\left(Z^{\prime \prime}\right)$ parts of complex impedance $\left(Z^{*}\right)$ were also used to calculate the real part $\left(\varepsilon^{\prime}\right)$ of permittivity $\left(\varepsilon^{*}\right)$, following the relation:

$$
\varepsilon^{\prime}=\frac{Z^{\prime \prime}}{\omega C_{o}\left(Z^{\prime 2}+Z^{\prime \prime 2}\right)} .
$$

Here $C_{o}$ is the vacuum capacitance and given by $\varepsilon_{o} A / t$, where $\varepsilon_{o}$ is a permittivity of free space and is equal to $8.85 \times$ $10^{-12} \mathrm{~F} / \mathrm{m}$. The angular frequency $\omega$ is equal to $\omega=2 \pi f$, where $f$ is the frequency of applied field.

\section{Results and Discussion}

3.1. X-Ray Diffraction Analysis. In order to investigate the effect of NaTf on the structure of chitosan-based polymer electrolyte, X-ray diffraction of pure NaTf, pure chitosan film, and their complexes have been performed. Figure 1 shows the $\mathrm{X}$-ray diffraction patterns of pure NaTf.

The crystalline peaks of pure NaTf salt can be detected at $2 \theta=8.5^{\circ}, 9.95^{\circ}, 16.8^{\circ}, 22.15^{\circ}, 26.25^{\circ}, 32.9^{\circ}, 35.6^{\circ}$, and $40.9^{\circ}$. The diffractograms of the pure chitosan film and chitosan: NaTf complexes, are illustrated in Figure 2.

Pure chitosan is semicrystalline. In the XRD pattern of pure chitosan, the broad peaks at around $2 \theta^{\circ}=15^{\circ}$ and $20^{\circ}$ indicate the average intermolecular distance of the crystalline part of pure chitosan membrane [22]. This rigid crystalline structure of chitosan is mainly maintained by intramolecular and intermolecular hydrogen bonds [23]. It can be noticed that, when 2 wt $\%$ of NaTf is added to chitosan, the intensity of the crystalline peaks of pure chitosan decreased and the peak at $2 \theta^{\circ} \sim 15^{\circ}$ has broadened, Figure 2(b). A new peak at $2 \theta^{\circ} \sim 11.6^{\circ}$ is observed for chitosan added with $4 \mathrm{wt} \%$ NaTf. On addition of more salt to chitosan, a number of new peaks are observed at $2 \theta=8.5^{\circ}, 18.3^{\circ}$, and $23^{\circ}$. In the CS10 an additional peak can be observed at $2 \theta=27^{\circ}$. According to Hashmi and Chandra [24], these new peaks may be due to some longrange order set by the presence of ion multiples. According to Sanders et al., [25], these new peaks are attributed to the formation of polymer-salt complexes rather than that of pure NaTf salt. In this work, the peaks observed in Figures 2(c) to 2(f) may be considered as chitosan-salt peaks that have been shifted to higher $2 \theta$ angles. The shifting of peaks is an indication that some long-range order has been set by the formation of chitosan-salt complexes at salt concentration greater than $2 \mathrm{wt} \%$. Figure 3 reveals the calculated coherent length at $2 \theta=21^{\circ}$, to find the amorphousity of the SPE films at different salt concentration.

In principle, Coherent length defines the crystallite size of polymer electrolytes. Based on Debye-Scherrer equation, the broader the diffraction peak width, the shorter the crystallite size. Samples with lower crystallinity exhibits higher ionic conductivity [26]. Thus the decrease in intensity and 


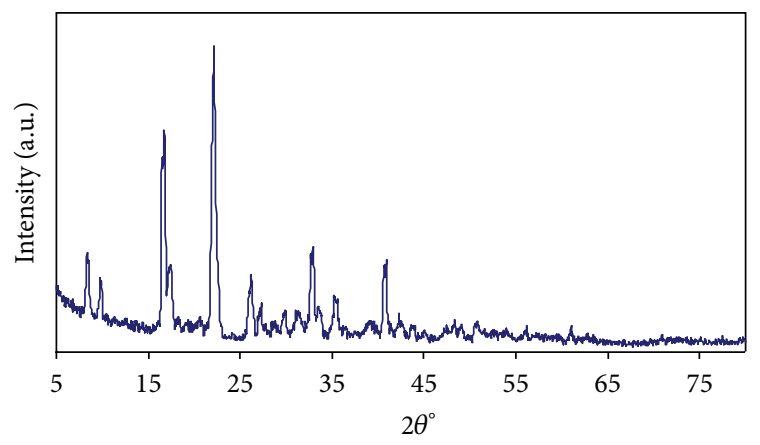

FIgURE 1: X-ray diffraction pattern of pure NaTf.

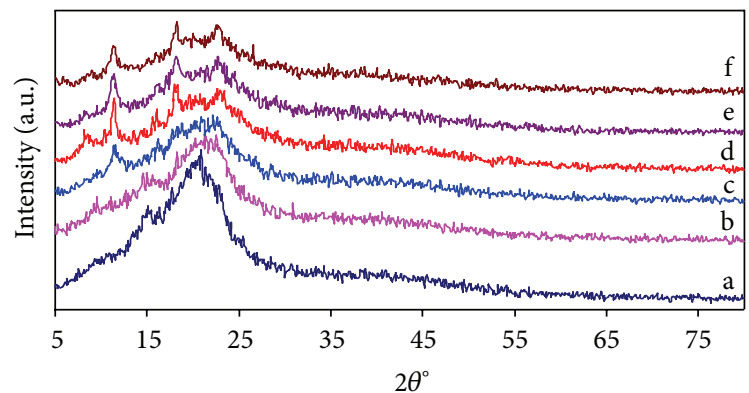

FIGURE 2: X-ray diffraction patterns of (a) CS0, (b) CS2, (c) CS4, (d) CS6, (e) CS8, and (f) CS10.

broadening of the peaks indicates the increase in amorphous region as a result of disruption of the crystalline domain of the chitosan by the NaTf salt.

3.2. FTIR Study. The most frequently performed observations to confirm the complexation of the polymer host with salts are variation in intensity of the bands, shifting of the bands with respective to the salt content [27]. Figures 4(a)-4(c) represent the FTIR spectrum of chitosan and chitosan:NaTf complexes in the wave number region between (a) $700 \mathrm{~cm}^{-1}$ and $1300 \mathrm{~cm}^{-1}$, (b) $1400 \mathrm{~cm}^{-1}$ and $1800 \mathrm{~cm}^{-1}$ and (c) $3000 \mathrm{~cm}^{-1}$, and $3800 \mathrm{~cm}^{-1}$.

Although there is possibility of overlapping between the $\mathrm{N}-\mathrm{H}$ and the $\mathrm{O}-\mathrm{H}$ stretching vibrations, the strong broad band at $3300-3500 \mathrm{~cm}^{-1}$ (Figure $4(\mathrm{a})$ ) is characteristic of the $\mathrm{N}-\mathrm{H}$ stretching vibration. The significant decrease of transmittance intensity and shifting in this band region as can be seen in Table 1 indicates that the $\mathrm{N}-\mathrm{H}$ vibration was affected by the attachment of the cation salt [28].

It can be noticed from Table 1 that there is a shifting in the carboxamide $(\mathrm{O}=\mathrm{C}-\mathrm{NHR})$ and amine $\left(\mathrm{NH}_{2}\right)$ bands which significantly confirms that complexation has occurred between chitosan and NaTf salt at the nitrogen and oxygen atoms of the amine and carboxamide groups, respectively [29]. The shifting and decrease in intensity are attributable to the fact that the attachment of cation salt to nitrogen and oxygen atoms can reduce the vibration intensity of the $\mathrm{N}-\mathrm{H}$ or $\mathrm{O}=\mathrm{C}-\mathrm{NHR}$ bonds due to the molecular weight becoming greater after cation binding [28]. The shifting and

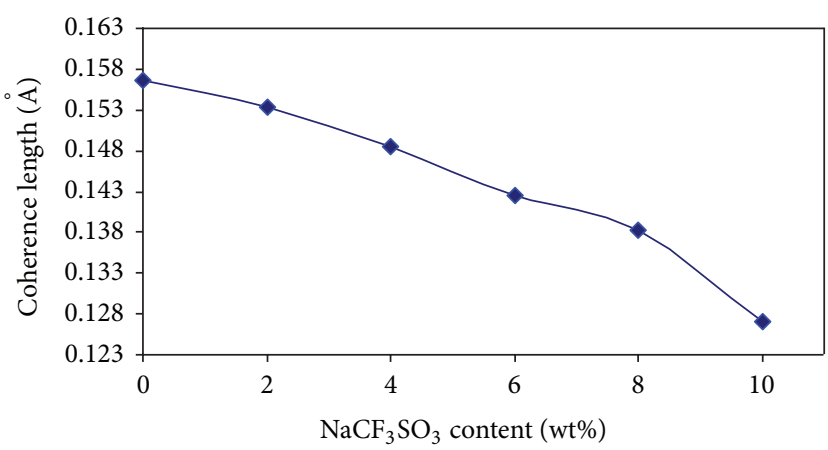

FIGURE 3: Coherence length of the chitosan:NaTf samples at $2 \theta^{\circ}=$ $21^{\circ}$.

TABLE 1: Assignments of FTIR bands for chitosan:NaTf solid electrolytes.

\begin{tabular}{lcccc}
\hline Samples & Wavenumbers $\left(\mathrm{cm}^{-1}\right)$ & & & \\
& $\mathrm{C}-\mathrm{O}$ & $\mathrm{NH}_{2}$ & $\mathrm{O}=\mathrm{C}-\mathrm{NHR}$ & $\mathrm{N}-\mathrm{H}$ \\
\hline CS0 & 1030 and 1069 & 1559 & 1648 & 3358 \\
CS2 & 1027 and 1070 & 1552 & 1640 & 3285 \\
CS4 & 1027 and 1068 & 1545 & 1636 & 3276 \\
CS6 & 1027 and 1069 & 1544 & 1637 & 3262 \\
CS8 & 1027 and 1068 & 1559 & 1636 & 3263 \\
CS10 & 1027 and 1069 & 1559 & 1637 & 3287 \\
\hline
\end{tabular}

a decrease in intensity of $\mathrm{C}-\mathrm{O}$ bands are also indicative that complexation between the cation of the salt and oxygen atom has occurred [29].

\subsection{Electrical Analysis}

3.3.1. Room Temperature Study of Dielectric Constant $\left(\varepsilon^{\prime}\right)$ and DC Conductivity $\left(\sigma_{\mathrm{dc}}\right)$. Figure 5 shows the variation of dielectric constant as a function of salt concentration at $303 \mathrm{~K}$. It can be seen that $\varepsilon^{\prime}$ increases with increase in salt concentration, that is, the presence of salt at certain concentrations causes an increase in the value of dielectric constant. Dielectric constant $\left(\varepsilon^{\prime}\right)$ is a measure of reduction of coulomb interaction between the ion pairs in polymer electrolytes. Thus dielectric property provided valuable information such as characteristic of the ionic/molecular interaction of the polymer electrolyte and the understanding of ion transport behavior as well. In all cases, the increase in dielectric constant implies the increase in the number of ions [30].

For a particular salt concentration, $\varepsilon^{\prime}$ values rise sharply towards low frequencies due to the electrode polarization (EP) effect. The low-frequency dispersion region is attributed to the contribution of charge accumulation at the electrode/electrolyte interface, that is, due to the free charges that build up at the interface between the material and the electrodes [31, 32]. Figure 6 shows the variation of DC conductivity with salt concentration at room temperature.

It is obvious from the previous results that the highest DC conductivity and dielectric constant are obtained for $10 \mathrm{wt} \%$ of NaTf, which is in good agreement with the XRD and FTIR results. This supports the structure properties 


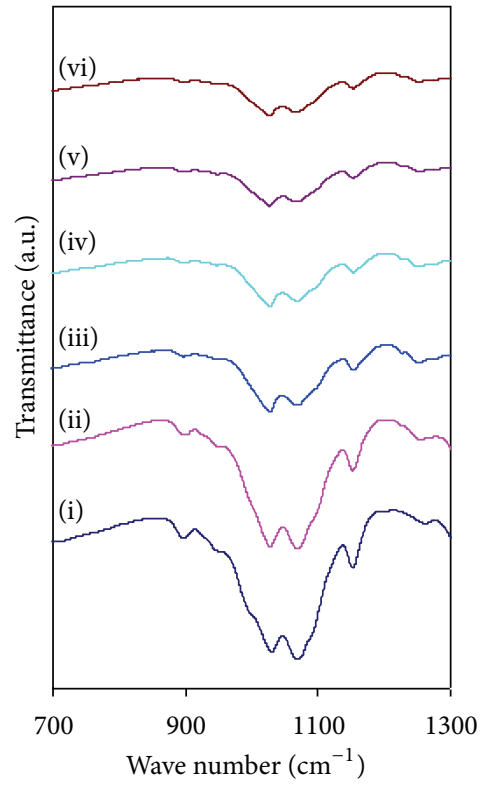

(a)

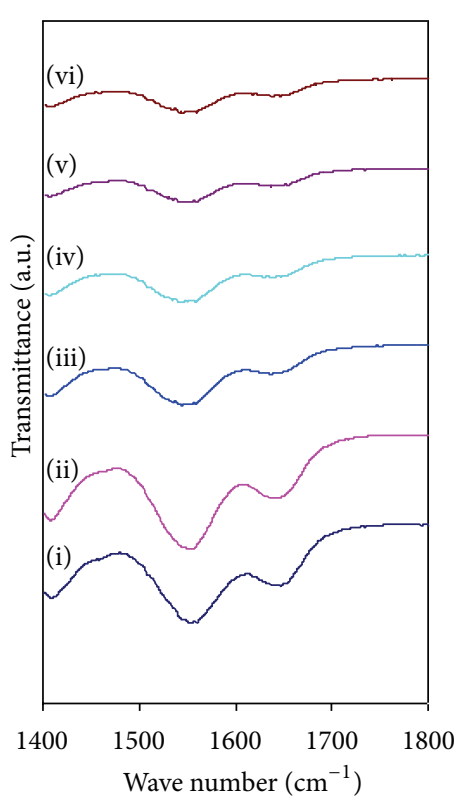

(b)

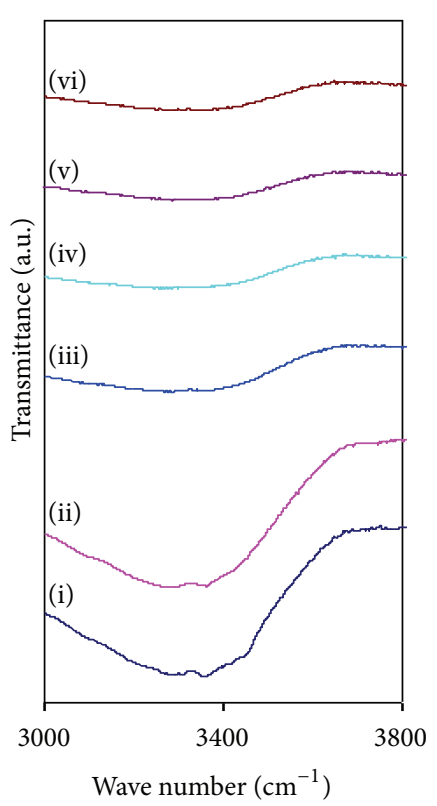

(c)

FIgURE 4: FTIR spectra of (i) CS0 (pure chitosan), (ii) CS2, (iii) CS4, (iv) CS6, (v) CS8, and (vi) CS10 in the region (a) $700 \mathrm{~cm}^{-1}$ to $1300 \mathrm{~cm}^{-1}$, (b) $1400 \mathrm{~cm}^{-1}$ to $1800 \mathrm{~cm}^{-1}$, and (c) $3000 \mathrm{~cm}^{-1}$ to $3800 \mathrm{~cm}^{-1}$.

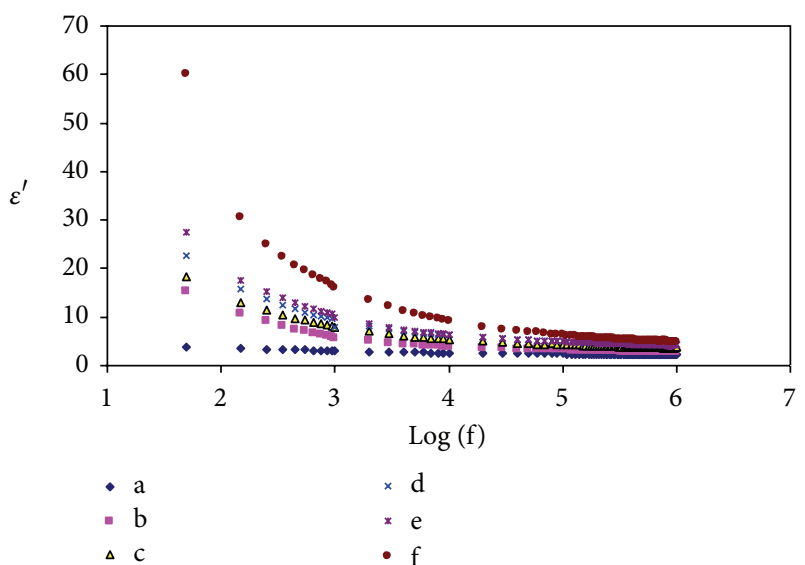

Figure 5: Compositional dependence of dielectric constant for (a) CS0, (b) CS2, (c) CS4, (d) CS6, (e) CS8, and (f) CS10.

relationship, that is, the more the system is amorphous, the more it is conductive. The question is that, what is the physics behind the relationship between dielectric constant and DC conductivity which is not given in Petrowsky and Frech $[20,21]$, publications? Generally, the ionic conductivity of polymer electrolyte depends on the number of the charge carriers and their mobility in the electrolyte and is often defined as follows [33]:

$$
\sigma=\sum n_{i} z_{i} \mu_{i}
$$

where $n_{i}, z_{i}$, and $\mu_{i}$ refer to the number of charge carriers, the ionic charge, and the ionic mobility, respectively. Thus, following (4) the enhancement in ionic conductivity can be

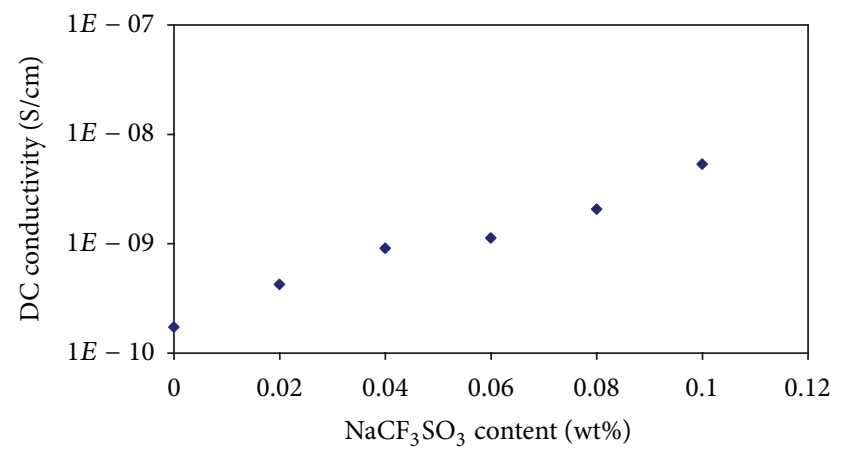

FIGURE 6: The DC ionic conductivity of chitosan with various concentrations of NaTf.

performed by increasing salt concentration or mobility. It can be seen that the ionic conductivity is increased with increasing salt concentration as presented in Figure 6. However, the charge carrier concentration, $n$, depended upon both the dissociation energy $U$ involved and dielectric constant $\varepsilon^{\prime}$ as [34],

$$
n=n_{o} \exp \left(-\frac{U}{\varepsilon^{\prime} K_{B} T}\right)
$$

where $K_{B}$ is the Boltzmann constant and $T$ is the absolute temperature.

Thus, an increase in DC conductivity means an increase in charge carrier concentration according to (4), and this is related to the dielectric constant according to (5). The behavior of DC conductivity (Figure 6) with salt concentration is 


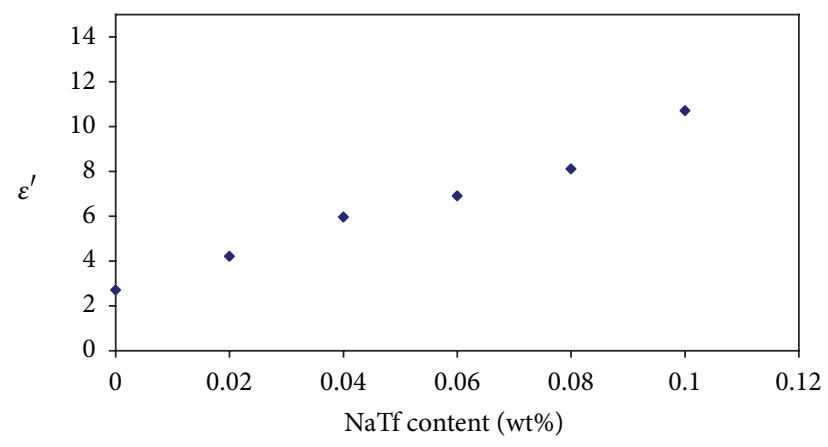

FIgURE 7: Dielectric constant (at $5 \mathrm{kHz}$ ) of chitosan with various concentrations of NaTf.

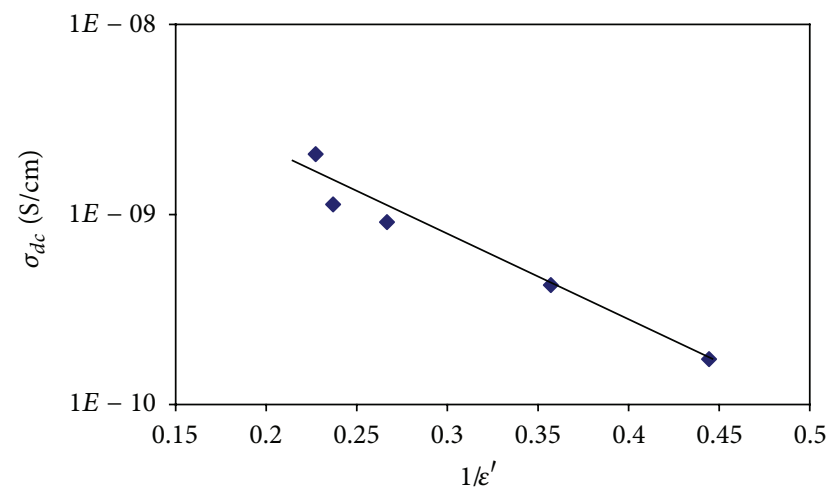

FIGURE 8: DC conductivity as a function of reciprocal of dielectric constant.

similar to dielectric constant (Figure 7) with salt concentration as shown later at a given frequency $(5 \mathrm{kHz})$.

The previous noticeable results indicate the fact that dielectric analysis is an informative technique to study conductivity behavior of solid polymer electrolytes; that is, the high dielectric constant means the high DC conductivity and vice versa. Finally, (4) and (5) lead us to a better conclusion that is the plotting of DC conductivity at different salt concentration on a log scale as a function of the reciprocal of dielectric constant should be a straight line as depicted in Figure 8.

The temperature dependence analysis of dielectric constant $\left(\varepsilon^{\prime}\right)$ may give further information between dielectric constant and conductivity.

3.3.2. Dielectric Constant $\left(\varepsilon^{\prime}\right)$ and DC Conductivity $\left(\sigma_{\mathrm{dc}}\right)$ as a Function of Temperature. The conductivity behavior of polymer electrolyte can be understood from dielectric analysis. The dielectric constant is a measure of stored charge, that is, directly related to the charge carriers. Figure 9 shows the variation of dielectric constant with frequency at selected temperatures for chitosan NaTf (CS10). At low frequency the mobile ions accumulate at the electrode/electrolyte interface. This gives a high value of dielectric constant $\left(\varepsilon^{\prime}\right)$. On the other hand, at high frequencies, periodic reversal of the electric field occurs so fast that there is no excess ion diffusion in the

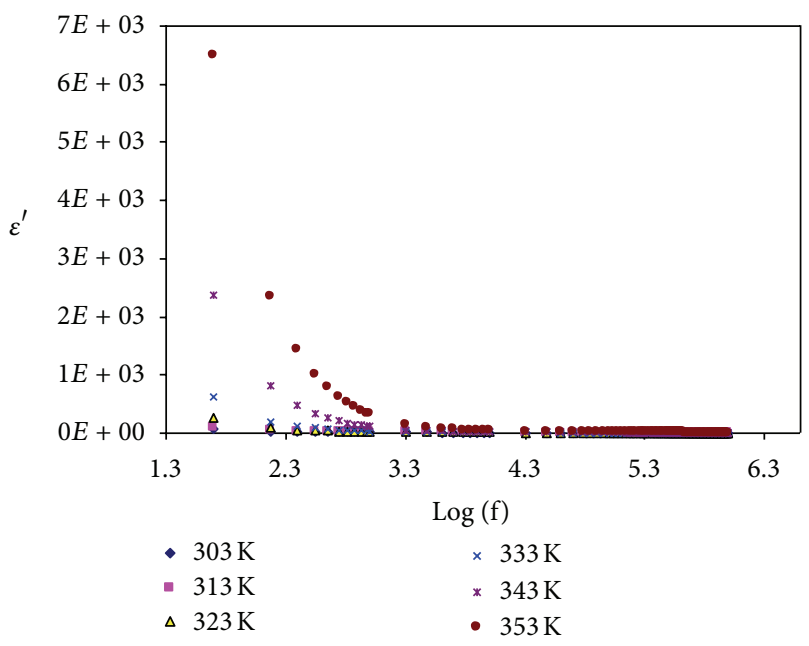

FIGURE 9: Frequency dependence of dielectric constant $\left(\varepsilon^{\prime}\right)$ for CS10, at selected temperatures.

direction of the field. Polarization due to charge accumulation decreases, leading to the observed decrease in dielectric constant [35].

It is obvious from Figure 9 that dielectric constant increases with increase in temperature due to the higher charge carrier density. The increase in dielectric constant means an increase in the DC conductivity which can be more understood from the following results.

Figures 10 and 11 show the variation of DC conductivity and dielectric constant with temperature for CS10 sample. It can be seen that the DC conductivity and dielectric constant show similar trends with temperature. This indicates a good relationship between DC conductivity and dielectric constant. It is obvious that at higher temperatures the DC conductivity and dielectric constant increased rapidly. This is due to the fact that at higher temperatures, movement of polymer chain segments is thermally enhanced and the dissociation of salts would increase assisting and resulting in the increase in ionic conductivity and dielectric constant [36]. Thus the concentration dependence of DC conductivity and dielectric constant (Figures 6 and 7) and the temperature dependence of DC conductivity and dielectric constant (Figures 10 and 11) reveal a strong relationship between DC conductivity and dielectric constant.

The plot of the logarithmic of DC conductivity $\left(\log \left(\sigma_{\mathrm{dc}}\right)\right)$ versus $1000 / T$ can be used to study the Arrhenius behavior or non-Arrhenius behavior of solid polymer electrolytes. The linear relations observed between $\log \left(\sigma_{\mathrm{dc}}\right)$ versus $1000 / T$ (Figure 12) for CS10 sample indicate the Arrhenius behavior of CS:NaTf SPEs [16]; that is, the temperature dependence of ionic conductivity satisfies the Arrhenius relation of the type

$$
\sigma_{\mathrm{dc}}(T)=\sigma_{o} e^{-E_{a} / K_{B} T},
$$

where $\sigma_{o}$ is a preexponential factor, $E_{a}$ is the activation energy, $K_{B}$ is the Boltzmann constant, and $T$ is the temperature $(\mathrm{K})$. The calculated $E_{a}$ value is $1.2 \mathrm{eV}$. 


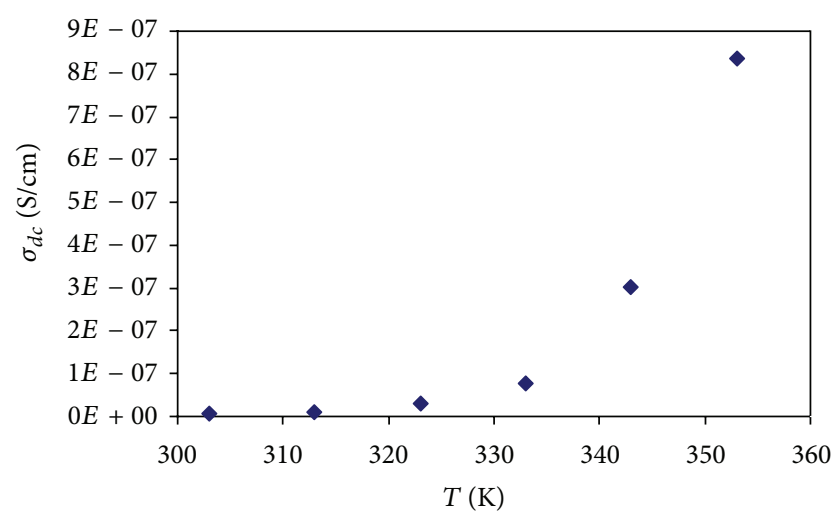

FIGURE 10: Variation of DC conductivity with temperature for CS10 sample.

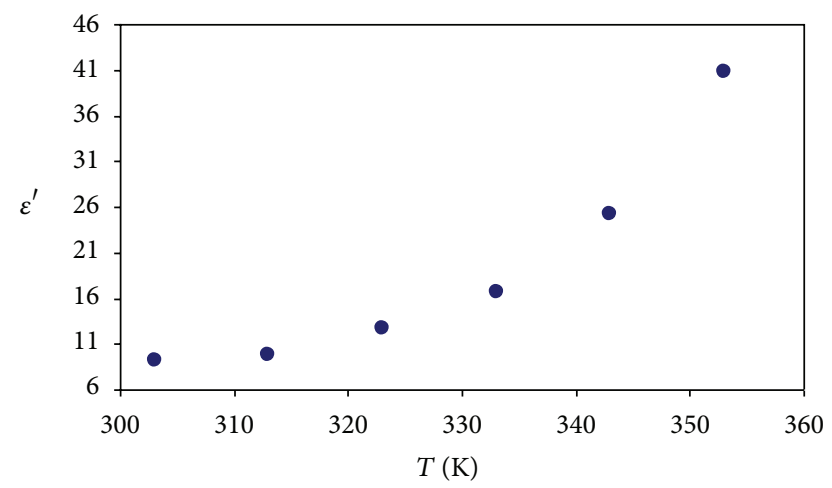

FIGURE 11: Variation of dielectric constant at $5 \mathrm{kHz}$ with temperature for CS10 sample.

The $\sigma_{\mathrm{dc}}$ and $\varepsilon^{\prime}$ relationship can be more understood by plotting $\sigma_{\mathrm{dc}}$ versus $\varepsilon^{\prime}$ at different temperatures as demonstrated by Petrowsky and Frech for organic liquid electrolytes. Figure 13 shows the smooth curve between DC conductivity and dielectric constant at different temperatures. This smooth curve can be viewed as an empirical description of the dependence of $\sigma_{\mathrm{dc}}$ on the dielectric constant $\left(\varepsilon^{\prime}\right)$ at different temperatures [20]. The dependence of DC conductivity on dielectric constant in polymer electrolytes can be explained as follows. In polar polymers when the temperature is raised, dielectric constant also enhances due to the facilitation in orientation of dipoles in the polar polymer [37]. As the dielectric constant increases with temperature, the degree of salt dissociation and redissociation of ion aggregates increases which result in an increase in number of free ions or charge carrier density [38] and hence an increase in DC conductivity. This curve reveals a strong dependence of DC conductivity on dielectric constant and temperature in the present solid polymer electrolytes. This result indicates the fact that DC conductivity is not only a function of temperature as exhibited in Arrhenius equation $\left(\sigma_{\mathrm{dc}}(T)=\sigma_{o} e^{-E_{a} / K_{B} T}\right)$ but also it is a function of dielectric constant $\left(\sigma_{\mathrm{dc}}\left(T, \varepsilon^{\prime}\right)=\right.$ $\left.\sigma_{o} e^{-E_{a} / K_{B} T}\right)$. Ion motion and conductivity are a very interesting and challenging problem in solid polymer electrolytes as

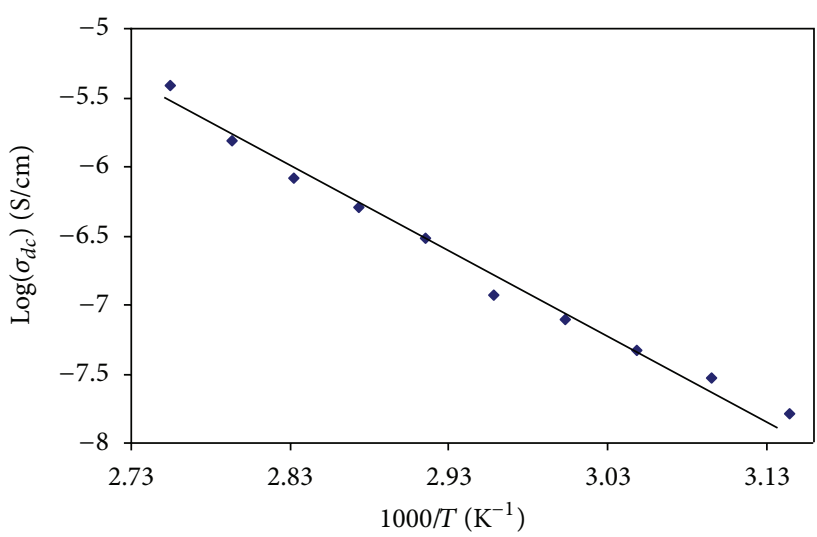

FIGURE 12: temperature dependence of DC ionic conductivity for CS10.

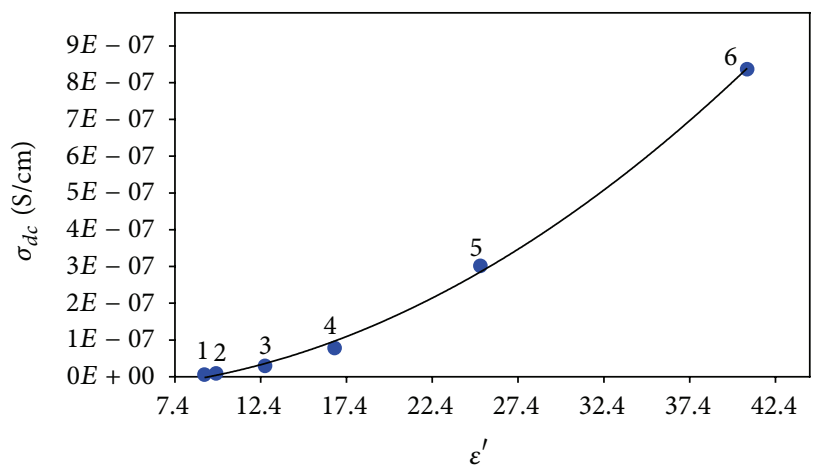

FIGURE 13: DC conductivity dependence on dielectric constant $\left(\varepsilon^{\prime}\right.$ at $5 \mathrm{kHz}$ ) at, (1) 303, (2) 313, (3) 323, (4) 333, (5) 343, and (6) $353 \mathrm{~K}$ for CS10 sample.

a branch of condensed matter physics. In conclusion, ionic transport in polymer electrolytes is a complicated subject and not completely understood, and this remains an obstacle in attaining the required room temperature conductivity. Thus the main goal of the present work which is the demonstration of the dependence of DC conductivity on dielectric constant in solid polymer electrolytes based on chitosan:NaTf has been successfully carried out experimentally.

\section{Conclusions}

X-ray diffraction shows that the amorphous phase greatly enhanced as a result of polymer-salt complexation. The coherent length study confirms the increase of amorphousness of the samples. The shifting and changes of the FTIR bands confirm the complexation between chitosan polar groups $\left(\mathrm{NH}_{2}\right.$ and $\left.\mathrm{O}=\mathrm{C}-\mathrm{NHR}\right)$ and the cation $\left(\mathrm{Na}^{+}\right)$of the sodium triflate salt. The high dielectric constant at low frequency is attributable to electrode polarization. The increase of dielectric constant is responsible for the increase of DC conductivity. The dependence of DC conductivity on both temperature and dielectric constant $\left(\sigma_{\left(\varepsilon^{\prime}, T\right)}=\sigma_{o} e^{\left(-E_{a} / K_{B} T\right)}\right)$ was demonstrated for CS:NaTf solid polymer electrolyte. The DC conductivity smoothly increases with increasing 
dielectric constant at different temperatures. The increase of DC conductivity with increasing temperature is due to the increase of carrier density which is related to the dependence of dielectric constant on temperature.

\section{Acknowledgments}

The authors gratefully acknowledge the financial support from UM in the form of grant (Grant no. PS214/2009A) for this research project. Shujahadeen B. Aziz thanks the Ministry of Higher Education and Scientific Research/Kurdistan Regional Government and Ahmed Esmael Nanakaly for the scholarship award.

\section{References}

[1] A. K. Thakur and S. A. Hashmi, "Polymer matrix-filler interaction mechanism for modified ion transport and glass transition temperature in the polymer electrolyte composites," Solid State Ionics, vol. 181, no. 27-28, pp. 1270-1278, 2010.

[2] R. N. Mason, L. Hu, D. T. Glatzhofer, and R. Frech, "Infrared spectroscopic and conductivity studies of poly(N-methylpropylenimine)/lithium triflate electrolytes," Solid State Ionics, vol. 180, no. 40, pp. 1626-1632, 2010.

[3] R. C. Agrawal, Y. K. Mahipal, and R. Ashrafi, "Materials and ion transport property studies on hot-press casted solid polymer electrolyte membranes: [(1 - x) PEO: $\mathrm{KIO}_{3}$ ]," Solid State Ionics, vol. 192, no. 1, pp. 6-8, 2011.

[4] H. M. J. C. Pitawala, M. A. K. L. Dissanayake, and V. A. Seneviratne, "Combined effect of $\mathrm{Al}_{2} \mathrm{O}_{3}$ nano-fillers and EC plasticizer on ionic conductivity enhancement in the solid polymer electrolyte (PEO) ${ }_{9}$ LiTf,' Solid State Ionics, vol. 178, no. 13-14, pp. 885-888, 2007.

[5] P.-L. Kuo, W.-J. Liang, and T.-Y. Chen, "Solid polymer electrolytes V: microstructure and ionic conductivity of epoxidecrosslinked polyether networks doped with $\mathrm{LiClO}_{4}$, Polymer, vol. 44, no. 10, pp. 2957-2964, 2003.

[6] R. Jayakumar, M. Prabaharan, S. V. Nair, and H. Tamura, "Novel chitin and chitosan nanofibers in biomedical applications," Biotechnology Advances, vol. 28, no. 1, pp. 142-150, 2010.

[7] P. Bai, F. Cao, X. Lan et al., "Chitosan gel beads immobilized $\mathrm{Cu}$ (II) for selective adsorption of amino acids," Journal of biochemical and biophysical methods, vol. 70, no. 6, pp. 903-908, 2008.

[8] G. Lu, L. Kong, B. Sheng, G. Wang, Y. Gong, and X. Zhang, "Degradation of covalently cross-linked carboxymethyl chitosan and its potential application for peripheral nerve regeneration," European Polymer Journal, vol. 43, no. 9, pp. 3807-3818, 2007.

[9] L. S. Ng and A. A. Mohamad, "Protonic battery based on a plasticized chitosan- $\mathrm{NH}_{4} \mathrm{NO}_{3}$ solid polymer electrolyte," Journal of Power Sources, vol. 163, no. 1, pp. 382-385, 2006.

[10] A. S. A. Khiar, R. Puteh, and A. K. Arof, "Conductivity studies of a chitosan-based polymer electrolyte," Physica B, vol. 373, no. 1, pp. 23-27, 2006.

[11] Z. Osman, Z. A. Ibrahim, and A. K. Arof, "Conductivity enhancement due to ion dissociation in plasticized chitosan based polymer electrolytes," Carbohydrate Polymers, vol. 44, no. 2, pp. 167-173, 2001.

[12] M. H. Buraidah, L. P. Teo, S. R. Majid, and A. K. Arof, "Ionic conductivity by correlated barrier hopping in $\mathrm{NH}_{4} \mathrm{I}$ doped chitosan solid electrolyte," Physica B, vol. 404, no. 8-11, pp. 13731379, 2009.

[13] M. F. Z. Kadir, S. R. Majid, and A. K. Arof, "Plasticized chitosanPVA blend polymer electrolyte based proton battery," Electrochimica Acta, vol. 55, no. 4, pp. 1475-1482, 2010.

[14] R. H. Y. Subban, A. K. Arof, and S. Radhakrishna, "Polymer batteries with chitosan electrolyte mixed with sodium perchlorate," Materials Science and Engineering B, vol. 38, no. 1-2, pp. 156-160, 1996.

[15] N. M. Morni, N. S. Mohamed, and A. K. Arof, "Silver nitrate doped chitosan acetate films and electrochemical cell performance," Materials Science and Engineering B, vol. 45, no. 1-3, pp. 140-146, 1997.

[16] S. B. Aziz, Z. H. Z. Abidin, and A. K. Arof, "Effect of silver nanoparticles on the DC conductivity in chitosansilver triflate polymer electrolyte," Physica B, vol. 405, no. 21, pp. 4429-4433, 2010.

[17] S. L. Agrawal, M. Singh, M. Tripathi, M. M. Dwivedi, and K. Pandey, "Dielectric relaxation studies on $\left[\mathrm{PEO}-\mathrm{SiO}_{2}\right]: \mathrm{NH}_{4} \mathrm{SCN}$ nanocomposite polymer electrolyte films," Journal of Materials Science, vol. 44, no. 22, pp. 6060-6068, 2009.

[18] D. K. Pradhan, R. N. P. Choudhary, and B. K. Samantaray, "Studies of dielectric relaxation and AC conductivity behavior of plasticized polymer nanocomposite electrolytes," International Journal of Electrochemical Science, vol. 3, pp. 597-608, 2008.

[19] M. Okutan and E. Şentürk, " $\beta$ dielectric relaxation mode in side-chain liquid crystalline polymer film," Journal of NonCrystalline Solids, vol. 357, no. 14, pp. 1526-1530, 2008.

[20] M. Petrowsky and R. Frech, "Temperature dependence of ion transport: the compensated arrhenius equation," Journal of Physical Chemistry B, vol. 113, no. 17, pp. 5996-6000, 2009.

[21] M. Petrowsky and R. Frech, "Salt concentration dependence of the compensated Arrhenius equation for alcohol-based electrolytes," Electrochimica Acta, vol. 55, no. 4, pp. 1285-1288, 2010.

[22] F. Göktepe, S. Ü. Çelik, and A. Bozkurt, "Preparation and the proton conductivity of chitosan/poly(vinyl phosphonic acid) complex polymer electrolytes," Journal of Non-Crystalline Solids, vol. 354, no. 30, pp. 3637-3642, 2008.

[23] Y. Wan, K. A. M. Creber, B. Peppley, and V. T. Bui, "Chitosanbased solid electrolyte composite membranes. I. Preparation and characterization," Journal of Membrane Science, vol. 280, no. 1-2, pp. 666-674, 2006.

[24] S. A. Hashmi and S. Chandra, "Experimental investigations on a sodium-ion-conducting polymer electrolyte based on poly(ethylene oxide) complexed with $\mathrm{NaPF}_{6}$," Materials Science and Engineering B, vol. 34, no. 1, pp. 18-26, 1995.

[25] R. A. Sanders, A. G. Snow, R. Frech, and D. T. Glatzhofer, "A spectroscopic and conductivity comparison study of linear poly(N-methylethylenimine) with lithium triflate and sodium triflate," Electrochimica Acta, vol. 48, no. 14-16, pp. 2247-2253, 2003.

[26] S. Ramesh, C.-W. Liew, and K. Ramesh, "Evaluation and investigation on the effect of ionic liquid onto PMMA-PVC gel polymer blend electrolytes," Journal of Non-Crystalline Solids, vol. 357, no. 10, pp. 2132-2138, 2011.

[27] K. K. Kumar, M. Ravi, Y. Pavani, S. Bhavani, A. K. Sharma, and V. V. R. N. Rao, "Investigations on the effect of complexation of $\mathrm{NaF}$ salt with polymer blend (PEO/PVP) electrolytes on ionic conductivity and optical energy band gaps," Physica B, vol. 406, no. 9, pp. 1706-1712, 2011. 
[28] D. Wei, W. Sun, W. Qian, Y. Ye, and X. Ma, “The synthesis of chitosan-based silver nanoparticles and their antibacterial activity," Carbohydrate Research, vol. 344, no. 17, pp. 2375-2382, 2009.

[29] M. H. Buraidah and A. K. Arof, "Characterization of chitosan/PVA blended electrolyte doped with $\mathrm{NH}_{4} \mathrm{I}$," Journal of Non-Crystalline Solids, vol. 357, no. 16-17, pp. 3261-3266, 2011.

[30] B. C. Ng, H. Y. Wong, K. W. Chew, and Z. Osman, "Development and characterization of Poly- $\varepsilon$-caprolactone-based polymer electrolyte for lithium rechargeable battery," International Journal of Electrochemical Science, vol. 6, no. 9, pp. 4355-4364, 2011.

[31] S. Selvasekarapandian, R. Baskaran, and M. Hema, "Complex AC impedance, transference number and vibrational spectroscopy studies of proton conducting PVAc- $\mathrm{NH}_{4} \mathrm{SCN}$ polymer electrolytes," Physica B, vol. 357, no. 3-4, pp. 412-419, 2005.

[32] J. Malathi, M. Kumaravadivel, G. M. Brahmanandhan, M. Hema, R. Baskaran, and S. Selvasekarapandian, "Structural, thermal and electrical properties of PVA- $\mathrm{LiCF}_{3} \mathrm{SO}_{3}$ polymer electrolyte," Journal of Non-Crystalline Solids, vol. 356, no. 43, pp. 2277-2281, 2010.

[33] Y. W. Chen-Yang, Y. T. Chen, H. C. Chen, W. T. Lin, and C. H. Tsai, "Effect of the addition of hydrophobic clay on the electrochemical property of polyacrylonitrile $/ \mathrm{LiClO}_{4}$ polymer electrolytes for lithium battery," Polymer, vol. 50, no. 13, pp. 2856-2862, 2009.

[34] A. Awadhia and S. L. Agrawal, "Structural, thermal and electrical characterizations of PVA:DMSO: $\mathrm{NH}_{4} \mathrm{SCN}$ gel electrolytes," Solid State Ionics, vol. 178, no. 13-14, pp. 951-958, 2007.

[35] C. V. S. Reddy, X. Han, Q. Zhu, L. Mai, and W. Chen, "Dielectric spectroscopy studies on (PVP + PVA) polyblend film," Microelectronic Engineering, vol. 83, no. 2, pp. 281-285, 2006.

[36] J. Y. Kim and S. H. Kim, "Ionic conduction behavior of network polymer electrolytes based on phosphate and polyether copolymers," Solid State Ionics, vol. 124, no. 1, pp. 91-99, 1999.

[37] A. Awadhia, S. K. Patel, and S. L. Agrawal, "Dielectric investigations in PVA based gel electrolytes," Progress in Crystal Growth and Characterization of Materials, vol. 52, no. 1-2, pp. 61-68, 2006.

[38] A. Karmakar and A. Ghosh, "Dielectric permittivity and electric modulus of polyethylene oxide (PEO)- $\mathrm{LiClO}_{4}$ composite electrolytes," Current Applied Physics, vol. 12, no. 2, pp. 539-543, 2012. 

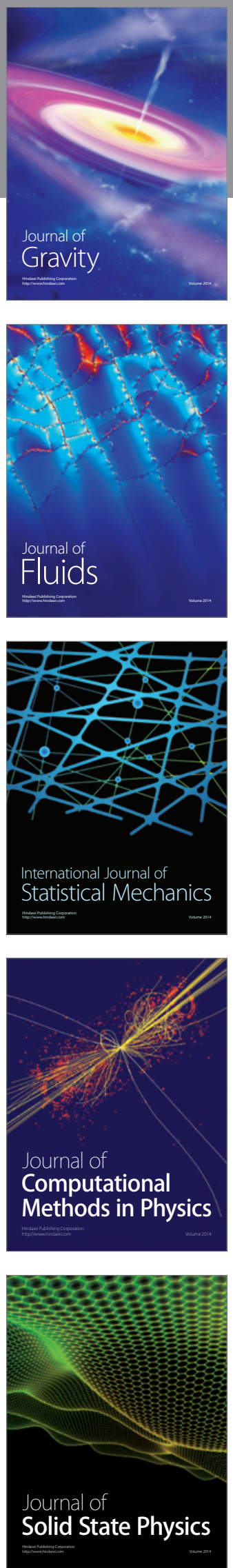

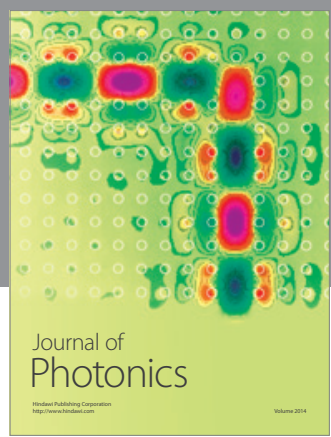

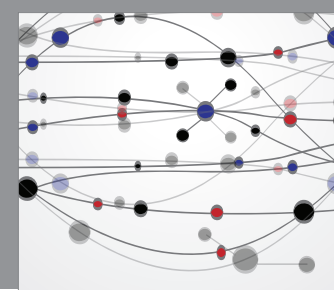

The Scientific World Journal

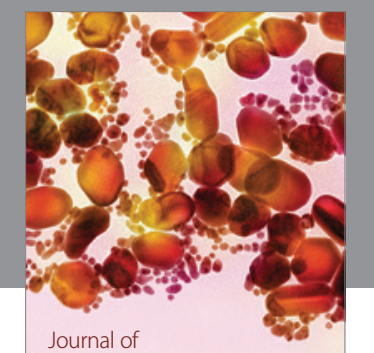

Soft Matter
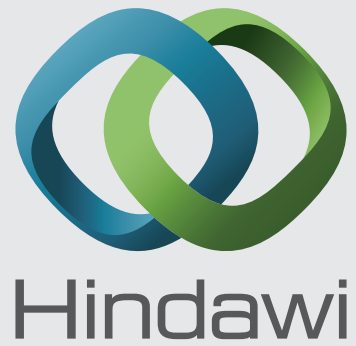

Submit your manuscripts at

http://www.hindawi.com
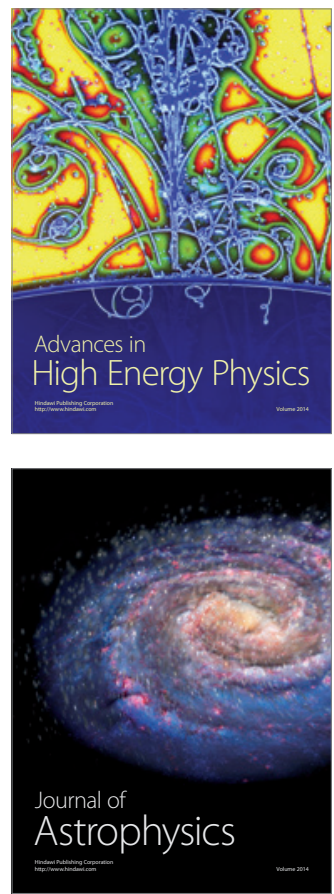
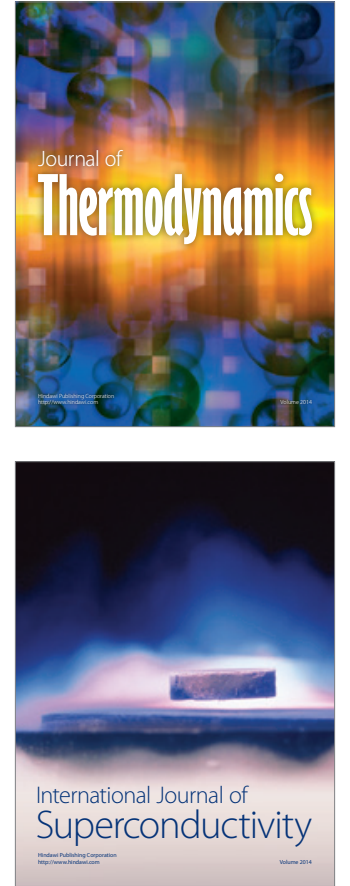
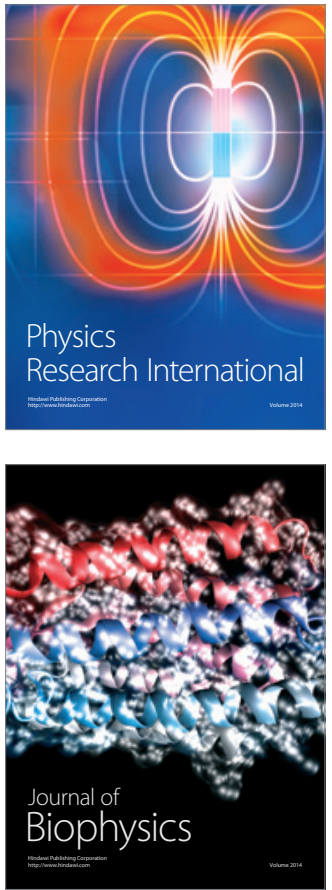
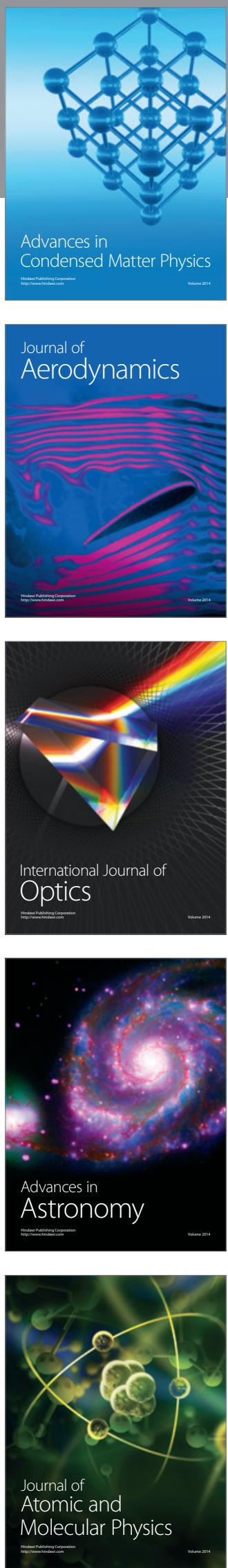